\title{
Prosthetic Rehabilitation of a Patient with Ectodermal Dysplasia
}

\author{
1Jyoti B Nadgere, ${ }^{2}$ Bhoomi A Parmar, ${ }^{3}$ Sabita M Ram, ${ }^{4}$ Naisargi P Shah
}

\begin{abstract}
Ectodermal dysplasia (ED) is a rare group of inherited disorders characterized by aplasia or dysplasia of two or more tissues of ectodermal origin, such as hair, nails, teeth, and skin. The dental characteristics of this syndrome include anodontia or hypodontia of the primary and/or permanent teeth, hypoplastic conical teeth, and underdevelopment of the alveolar ridges. Patients with ED have psychosocial issues due to the orofacial manifestations; therefore, restoring appearance and function is more challenging than usual. The options for a definitive treatment plan include removable, fixed, or implant-supported prostheses, single or in combination. This clinical report describes the prosthetic rehabilitation of a patient having ED.
\end{abstract}

Keywords: Anodontia, Ectodermal dysplasia, Flexible denture.

How to cite this article: Nadgere JB, Parmar BA, Ram SM, Shah NP. Prosthetic Rehabilitation of a Patient with Ectodermal Dysplasia. J Contemp Dent 2016;6(3):214-219.

Source of support: Nil

Conflict of interest: None

\section{INTRODUCTION}

Ectodermal dysplasia (ED) is defined by the National Foundation for Ectodermal Dysplasia as a genetic disorder in which there are congenital birth defects of two or more ectodermal structures. ${ }^{1}$

The syndrome involves overlapping features, thereby complicating a definitive classification. Lamartine in 2003, described various well-defined EDs as hypohidrotic (anhidrotic) or hidrotic (Clouston syndrome), ectrodactyly-ED-cleft syndrome (EEC), Rapp-Hodgkin syndrome, Hay-Wells syndrome, or ankyloblepharon ED. Usually, the ED is divided into two types based on the number and function of sweat glands as hypohidrotic (anhidrotic) ED (Christ-Siemens-Touraine syndrome) and hidrotic ED (Clouston syndrome). ${ }^{2}$ About 60 to $70 \%$ of the cases usually show manifestations restricted to

${ }^{1,3,4}$ Professor, ${ }^{2}$ Postgraduate student

${ }^{1-4}$ Department of Prosthodontics, Crown and Bridge, Mahatma Gandhi Mission's Dental College and Hospital, Navi Mumbai Maharashtra, India

Corresponding Author: Jyoti B Nadgere, Professor, Department of Prosthodontics, Crown and Bridge, Mahatma Gandhi Mission's Dental College and Hospital, Navi Mumbai, Maharashtra, India Phone: +919820641113, e-mail: jyotinadgere@gmail.com minimal hypodontia, aplastic or hypoplastic mammary glands, impaired lacrimal gland function, glaucoma, and increased susceptibility to allergic disorders, such as asthma or eczema. Typical general mental development, frontal bossing with characteristic reduction in amount of hair (hypotrichosis), absence of sweat glands (anhidrosis) resulting in temperature elevation, absence of sebaceous glands (asteatosis) resulting in dry skin, depressed nasal bridge, protuberant lips, prominent supraorbital ridges, sunken cheeks, wrinkled hyperpigmented skin around the eyes, senile appearance, and large low-set ears are characteristics commonly seen in individuals with ectodermal dysplasia. ${ }^{2}$

The oral manifestations include conical or peg-shaped teeth, hypodontia (partial absence of teeth), or complete anodontia (complete absence of teeth) of both the deciduous and the permanent dentition with malformation of any teeth that may be present, generalized spacing, underdeveloped alveolar ridges, and delayed eruption of permanent teeth. Even when complete anodontia exists, the growth of the jaw is not impaired. This would imply that the development of the jaws except for the alveolar process is not dependent upon the presence of teeth. ${ }^{8}$ However, since the alveolar process does not develop in the absence of teeth, there is a reduction in the normal vertical dimension resulting in the protuberant lips. The salivary glands including the intraoral accessory glands are sometimes hypoplastic in this disease.

This results in xerostomia, and the protuberant lips may be dry and cracked. ${ }^{3}$

An understanding of the ED patient's psychosocial status is crucial to any prosthodontic treatment effort. ${ }^{3}$ The unesthetic appearance that accompanies ED syndrome often has a negative psychological effect on the patient. Poor self-imaging, peer pressure, and school/ job-related discrimination have been directly related to psychological scarring experienced by ED patients. Providing expedient prosthodontics treatment to manage orofacial disfigurement may afford the patient some measure of confidence. ${ }^{3}$ In this article, a challenging case report of a patient with ED has been presented.

\section{CASE REPORT}

A 25-year-old female patient reported to the department with the chief complaint of missing teeth, inability to 
masticate, and unesthetic appearance. No siblings of the patient suffered from ED; her parents also appeared to be normal. At first, the patient was reluctant to come for treatment, but after her mother's insistence and explanation by the operator, she was well motivated to get treatment and she was enthusiastic to complete her treatment.

On extraoral examination, the patient exhibited classic features of ED including sunken nasal bridge, prominent forehead, and inverted lips (Figs 1A to C). Patient had short upper lip and did not have a clear speech. She had an ovoid facial form and concave profile. She had a reduced vertical dimension giving typical senile appearance. On examination, no abnormality with temporomandibular joint was seen.

On intraoral examination (Figs 2A to $\mathrm{C}$ ), the mouth opening was found to be restricted because of taut fibers in the buccal mucosa, which could be palpated. The patient presented partial anodontia with teeth present in the upper arch being 16, 15, 14, 13, 11, 21, 25, 26, and 27 and in lower arch being 45,41,31,32, 33, and 35, which were lingually tilted, creating a severe undercut in these regions. The alveolar ridges in both the arches were not fully developed, and the lower ridge was found to be almost flat; 11 and 21 were retroclined, 21 was fractured, 13 was extruded, and 14 was rotated. Grade II mobility with 41 and severe recession was seen. The periodontal status of the remaining teeth was fair. Tongue was normal in size, but showed restricted movements.

On orthopantograph radiographic examination, it was seen that the alveolar ridges appeared inadequate in height. The root length of all the teeth was found to be short and with receded pulp chambers. Bone appeared to be sparse.

As the patient had restricted mouth opening, it was not possible to place the stock metal tray; therefore, the flanges of the stock metal tray were trimmed and impressions were made for both the arches and poured in dental stone. However, because of short arches and restricted mouth opening, the impression did not come out well extended; a custom tray was then fabricated from autopolymerizing resin on the diagnostic cast. Using these custom trays, impression were made for the upper and lower arches in polyvinylsiloxane impression material (Fig. 3) and poured in dental stone. Facebow and interocclusal bite record in Aluwax were taken (Fig. 4). With the help of the facebow, the upper cast was mounted on the semiadjustable articulator, and with the help of interocclusal record the lower cast was mounted against the upper cast.

Taking the esthetics into consideration, a diagnostic wax-up for anterior teeth was done on the diagnostic casts (Fig. 5), and a putty index was prepared. Using
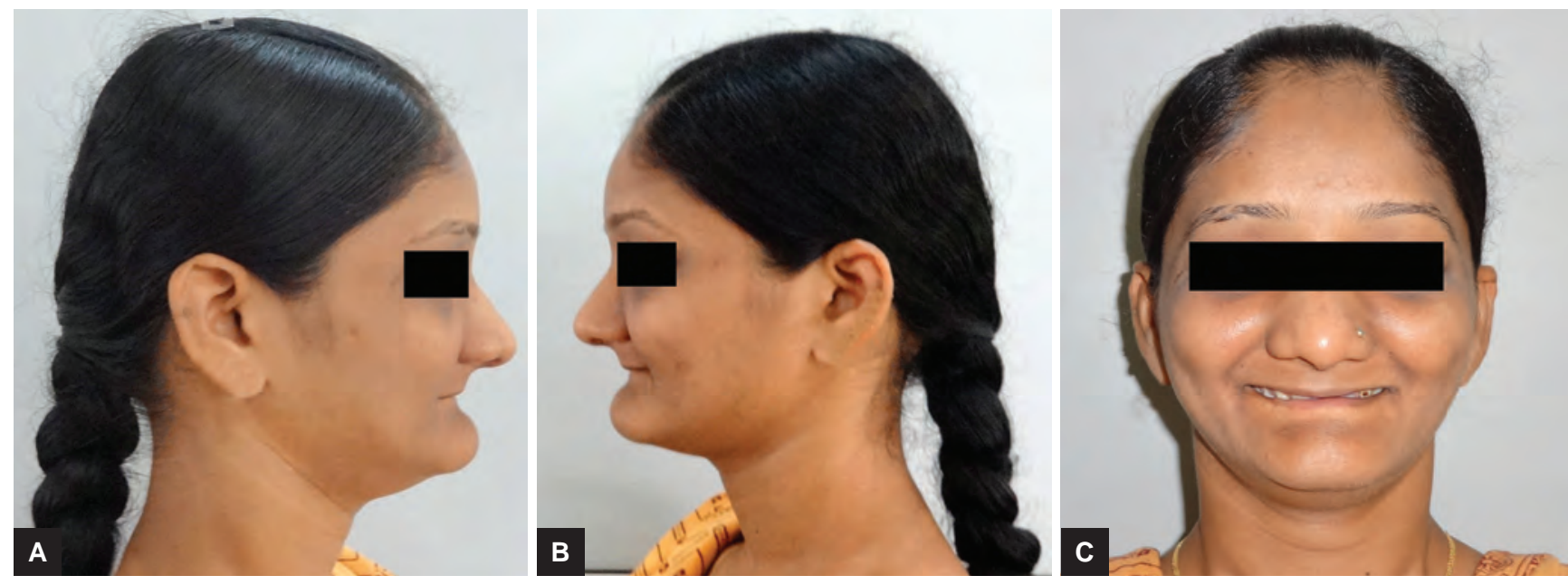

Figs 1A to C: Preoperative extraoral photographs
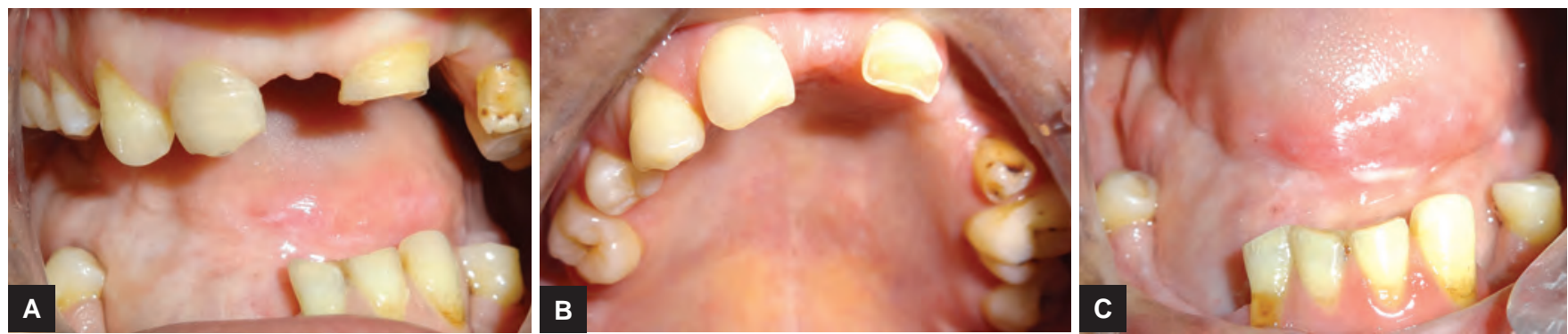

Figs 2A to C: Preoperative intraoral photographs 


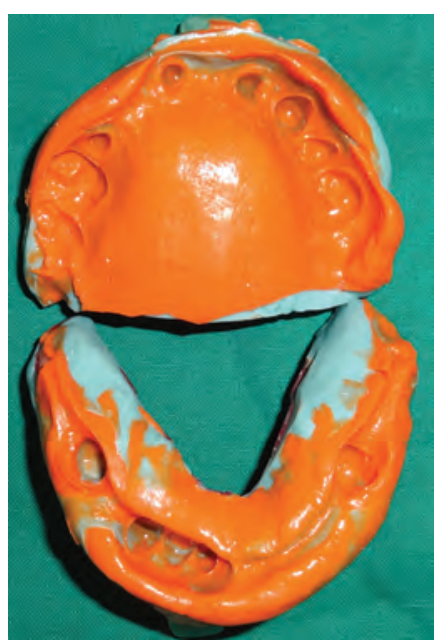

Fig. 3: Diagnostic impressions

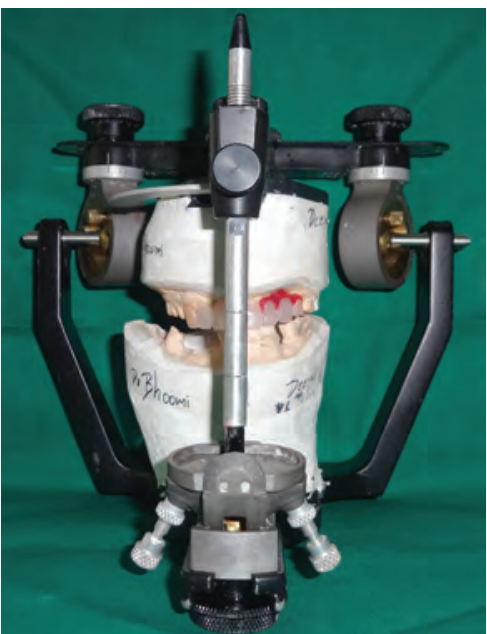

Fig. 5: Diagnostic wax-up

the putty index, provisionals were made in Protemp directly into patient's mouth, which was checked for esthetics and phonetics (Fig. 6); any changes required were directly corrected onto the provisional into the mouth and then incorporated in the diagnostic wax-up. Then posterior wax-up was done maintaining the occlusal plane, and putty index for the entire arch was made to be later used after preparation to get the provisional. Using putty index, the provisionals for the posterior teeth were fabricated and checked intraorally for occlusal plane and esthetics. After checking impression material to get a cast in dental stone, anterior and posterior provisional impressions were made in irreversible hydrocolloid.

According to the mock trial and final approval of patient, the following treatment plan was made for the patient: A multidisciplinary treatment was planned for the patient that involved endodontic treatment, periodontic management, and prosthetic rehabilitation. Oral prophylaxis was advised to the patient. As grade II mobility was present with 41, extraction was advised.

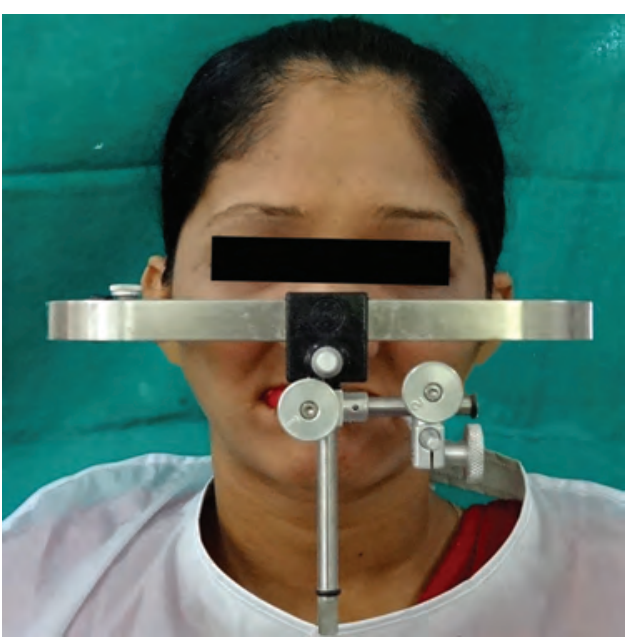

Fig. 4: Facebow registrationn

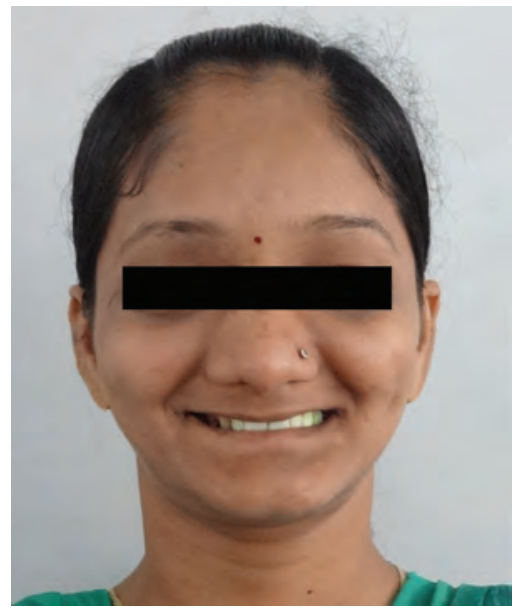

Fig. 6: Mock up trial

For the upper arch, endodontic treatment was advised with 13, 11, 21, and 25. Cast post was planned for 11 and 21, as they were retroclined and needed to be repositioned. The i-post with composite core was planned for 13 and 25. As there was uneven spacing present, it was found there was an overlapping of pontic areas on the abutment tooth structure so as to achieve tooth form, and esthetic addition of gingival porcelain in anterior region was planned. So, a final 7-unit ceramometal bridge was planned with $13,11,21$, and 25 as abutments for the upper arch. For the lower arch, endodontic treatment was planned for 31, 32, and 33. The i-post and composite core were planned for the same teeth. The composite buildup with 35 and 45 was planned to block the undercut. Hence, the final plan decided was with ceramometal crowns with 31,32 , and 33 , and because of severe undercut and limited mouth opening, a short-arch flexible denture for lower arch was decided upon. The entire treatment plan was explained to the patient and consent was taken.

After the preprosthetic treatment was completed, direct cast post patterns were fabricated with pattern 
resin for 11 and 21 by repositioning them and casting in $\mathrm{Ni}-\mathrm{Cr}$ alloy. The cast post was then cemented with zinc phosphate cement (Fig. 7). The i-post and composite core were done for $15,25,31,32$, and 33 .

Tooth preparation was carried out with 15, 13, 11, 21, $25,31,32$, and 33 (Figs $8 \mathrm{~A}$ and $\mathrm{B}$ ) to receive ceramometal restoration and equicrevicular finish lines were given. Mechanochemical gingival dilation was carried with knitted retraction cord impregnated in 15\% aluminum chloride hemostatic agent. Final impressions (Fig. 9) of both the arches were made using polyvinylsiloxane impression material by two-stage impression technique in the custom trays fabricated earlier and poured in die stone, and facebow was taken. Interocclusal record was taken in Aluwax. Provisionalization was done using the index mentioned before and Protemp (Figs 10A and B). The upper final cast with facebow was mounted on the semiadjustable articulator, and with the help of interocclusal record, the lower final cast was mounted against the upper final cast; wax patterns were fabricated (Fig. 11) and casted in $\mathrm{Ni}-\mathrm{Cr}$ alloy. Metal trial was done; copings were checked for the fit and clearance (Fig. 12). After metal trial, the ceramic buildup was done on the metal copings, and a bisque trial was done with final crowns. During bisque trial, the esthetics and phonetics were checked. The trial crowns were then glazed and cemented with zinc phosphate cement (Fig. 13). After cementation, the impression of both the arches was made (Fig. 14) and a jaw relation was taken; the casts were mounted on the articulator, and flexible denture for lower was fabricated (Fig. 15). The flexible denture was then inserted into the patient's mouth. The patient was educated about proper insertion and the removal of the prostheses and instructed about maintaining denture hygiene. Recall was done after 24 hours to make necessary adjustments. Patient was happy and satisfied with the treatment (Figs 16A and B).

\section{DISCUSSION}

The treatment of ED is quite challenging and should include a multidisciplinary approach. In this case, as there was grade II mobility with 41, extraction was advised. The central incisors were retroclined and with uneven spacings; cast posts were planned so that the angulation can be changed and tooth can be repositioned. The i-post with other teeth was planned because of better adaptation and less stress values in dentin. ${ }^{4}$

Ceramometal crowns were given for the fixed partial denture with the upper and lower arches because they provide good esthetics and better strength.

Use of gingival ceramic to restore missing soft and hard tissues simplifies and reduces the time and cost of treatment. Also, the esthetic results tend to be significantly better with the artificial gingiva. ${ }^{5}$



Fig. 7: Cast post fabricated and cemented
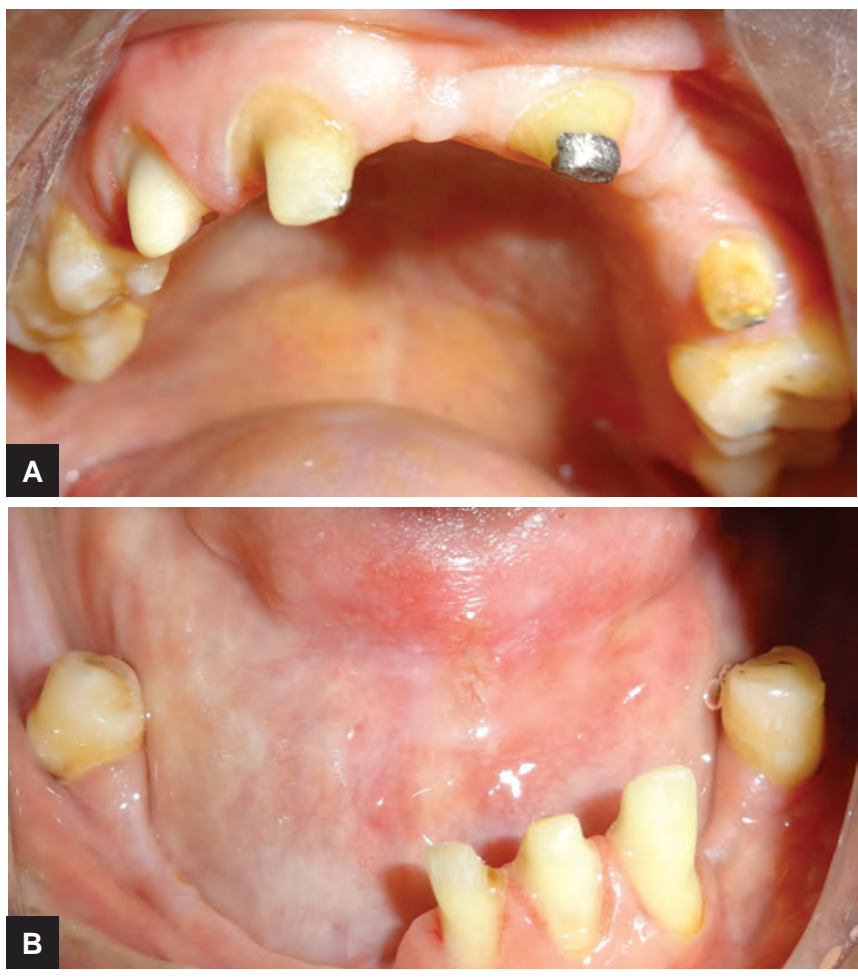

Figs 8A and B: Tooth preparation done for upper and lower arches

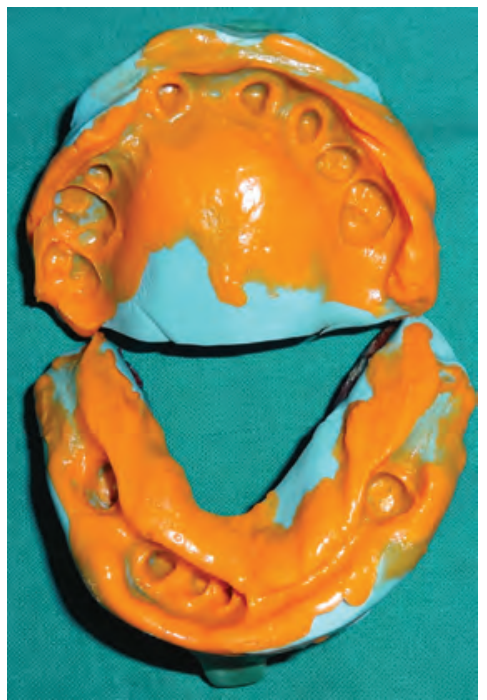

Fig. 9: Final impressions for upper and lower arches 

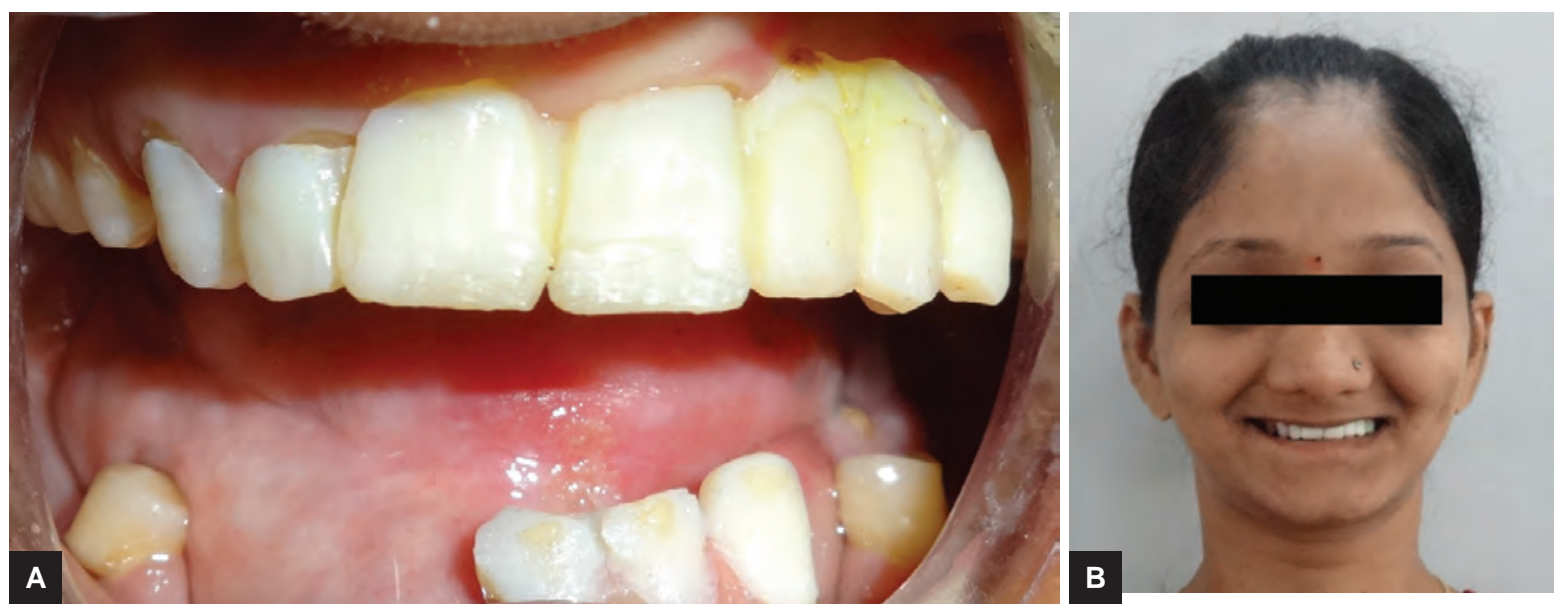

Figs $10 \mathrm{~A}$ and $\mathrm{B}$ : Provisionalization

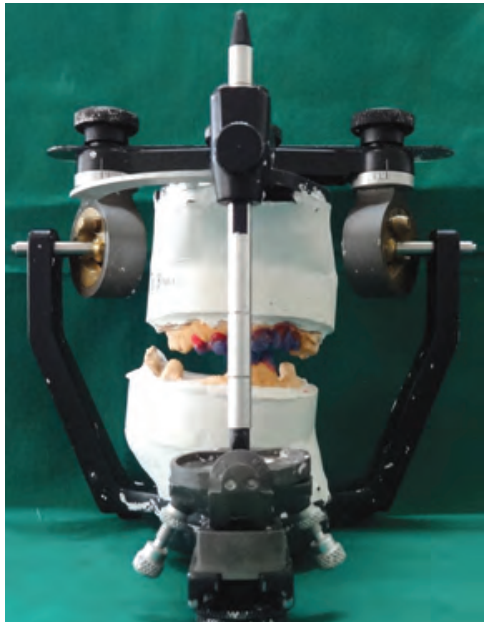

Fig. 11: Wax patterns prepared on upper and lower casts

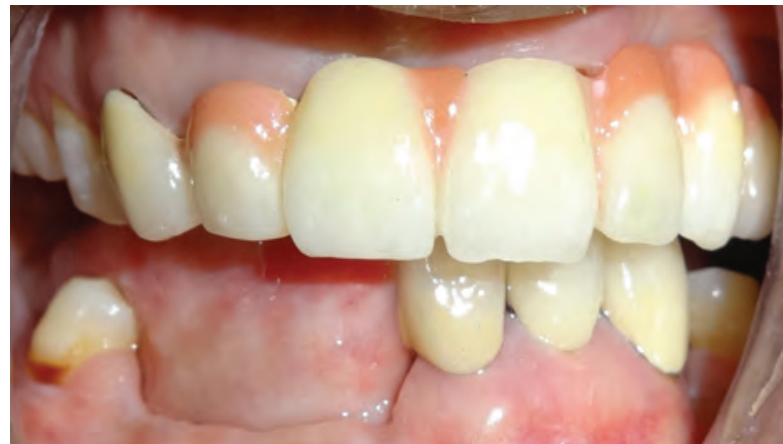

Fig. 13: Ceramo-metal crowns cemented for upper and lower arches

In this case, as the patient had severe undercut and restricted mouth opening, a flexible denture for lower arch was planned. Flexible dentures are fabricated from thermoplastic nylon. ${ }^{6-10}$

In this case, the patient was very comfortable with the flexible partial denture due to its light weight and was quite satisfied with the esthetics because of absence of the metallic part usually seen in other cast partial dentures. Good retention was observed, and the parents reported a significant improvement in terms of speech and mastication.

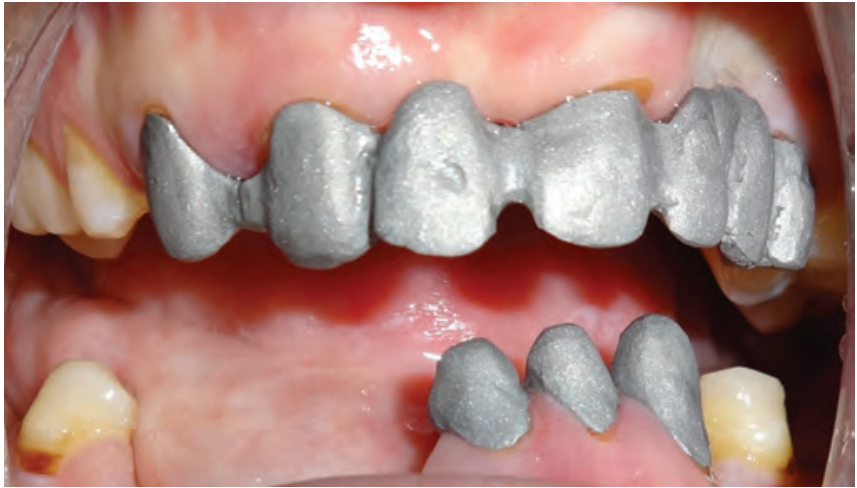

Fig. 12: Metal copings trial for upper and lower arches

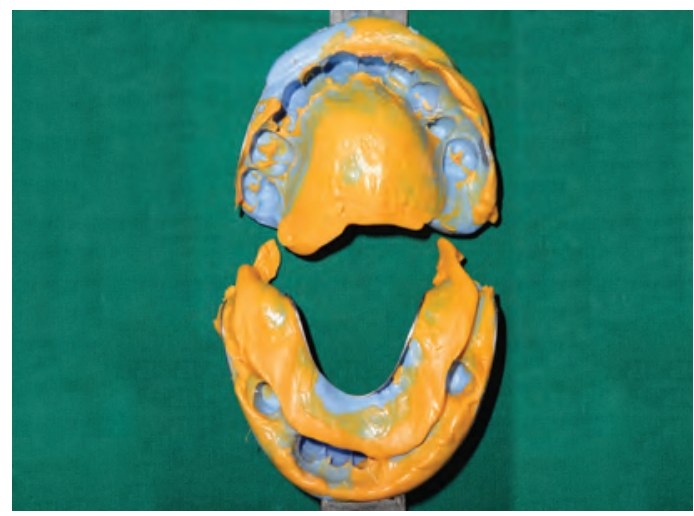

Fig. 14: Impressions for upper and lower arches

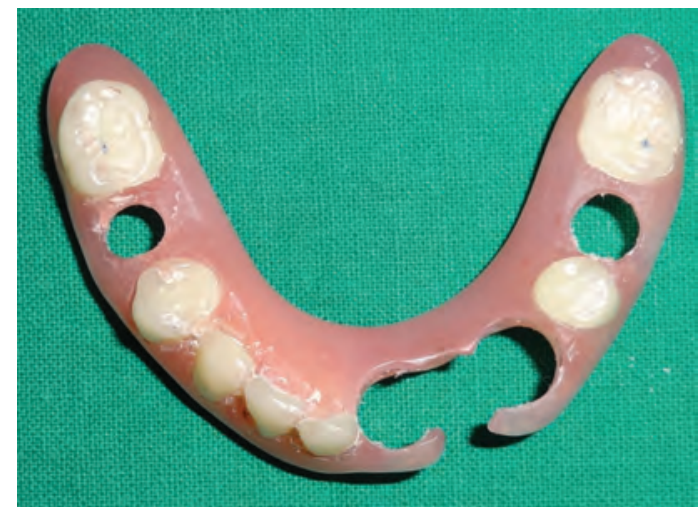

Fig. 15: Flexible denture 



Figs 16A and B: Postoperative intraoral

\section{CONCLUSION}

An understanding of the ED patient's psychosocial status is crucial to any prosthodontic treatment effort. The unesthetic appearance not just affects the normal living, but also declines the patient's self-confidence. With proper care and prosthodontic treatment, the patient can enjoy a relatively normal life.

\section{REFERENCES}

1. Murthy JV, Vaze R. Prosthetic management of an ectodermal dysplasia: a case report. People's J Sci Res 2010 Jul;3(2):37-40.

2. Tarjan I, Gabris K, Rozsa N. Early prosthetic treatment of patients with ectodermal dysplasia: a clinical report. J Prosthet Dent 2005 May;93(5):419-424.

3. Hickey A, Vergo TJ Jr. Prosthodontic consideration in the treatment of patients with maxillary and mandibular deficiencies. J Prosthet Dent 1991 Nov;66(5):645-649.

4. Mengal GP, Nadgere J, Ram SM, Shah N. A comparative evaluation of stress distribution by three different designs of prefabricated metal posts on endodontically treated permanent maxillary central incisor. A three dimensional finite element study. J Contemp Dent 2015;3:123-130.

5. Coachman C, Salama M, Garber D, Calamita M, Salama H, Cabral G. Prosthetic gingival reconstruction in a fixed partial restoration. Part 1: Introduction to artificial gingiva as an alternative therapy. Int J Periodontics Restorative Dent 2009 Oct;29(5):471-477.

6. Sharma A, Shashidhara HS. A review: flexible removable partial dentures. J Dent Med Sci 2014;13(12):58-62.

7. Hickey AJ, Vergo TJ Jr. Prosthetic treatments for patients with ectodermal dysplasia. J Prosthet Dent 2001 Oct;86(4): 364-368.

8. Crawford PJ, Alred MJ, Clarke A. Clinical and radiographic dental findingsin X-linked hypohidrotic ectodermal dysplasia. J Med Genet 1991 Mar;28(3):181-185.

9. Weech AA. Hereditary ectodermal dysplasia (congenital ectodermal defect): a report of two cases. Am J Dis Child 1929 Apr;37(4):766-790.

10. Sunitha NS, Jagadeesh KN, Kalavathi SD, Kashinath KR. Flexible dentures - an alternate for rigid dentures? J Dent Sci Res 2010 Feb;1:74-79. 